\title{
Learning Professional Knowledge: Bachelor Nursing Students' Experiences in Learning and Knowledge Quality Outcomes in a Competence-Based Curriculum
}

\author{
Ria den Hertog ${ }^{1,2} \cdot$ Henny P. A. Boshuizen ${ }^{1}$ \\ Received: 2 July 2020 / Accepted: 28 June 2021 / Published online: 18 September 2021 \\ (C) The Author(s) 2021
}

\begin{abstract}
Since decades, nursing education struggles with a persistent gap between the theoretical knowledge offered in the study program and its application in professional practice. To bridge this gap competence-based curricula were developed with instructional designs as authentic learning contexts and self-directed learning. In this project we explored final year Bachelor Nursing (BN) students' experiences in learning in a newly developed curriculum, and their knowledge quality outcomes and the degree of agreement with knowledge requirements. An instrumental multiple case study was conducted with interviews, concept mapping and a domain knowledge list. Results show that a third of the participants had positive learning experiences and got high appraisals for their knowledge quality. Similar to the medium and low scoring participants, they developed instrumental knowledge but integrated other forms of learning into a system of meaning, which is needed to solve non-routine problems in future practice. Medium and low scoring participants did not profit from learning in authentic contexts and selfdirected learning. In conclusion, developing sufficient professional knowledge in a constructivist competence-based curriculum is influenced by students' intrinsic motivation to build a strong knowledge base, by their perception of how to learn and use professional knowledge, and their expectations of the degree of supervision and guidance by the teacher. It is recommended to evaluate the extent to which the intended curriculum is being taught.
\end{abstract}

Keywords Bachelor nursing students · Theory-practice gap · Competence-based curriculum $\cdot$ Learning experiences $\cdot$ Authentic contexts $\cdot$ Self-directed learning

Ria den Hertog fdhertog@che.nl

1 Open University Faculty of Educational Sciences, Heerlen, the Netherlands

2 Christian University of applied sciences Ede, Ede, the Netherlands 


\section{Introduction}

Learning professional knowledge consists of learning theoretical, experiential, selfregulative and social-cultural knowledge to understand what is happening in professional practice and why, and how to act as may be expected of a professional. Higher vocational education curricula offer programmes to students to learn the shared body of knowledge of their future professional domain. The body of knowledge consists largely of theoretical knowledge. Theoretical knowledge is universal, formal and explicit, and consists of facts, concepts, principles and theories (Eraut, 1994; Novak, 2010). However, theoretical knowledge is not sufficient to perform the tasks in practice. An equally important form of professional knowledge is practical or experiential knowledge, which is often implicit and embedded in skills (e.g., Griffiths \& Guile, 2003). For conscious storage of knowledge acquired in practice, learners need to explain and conceptualize experiential knowledge with the help of theoretical models in order to understand practice and act professionally (Leinhardt et al., 1995; Tynjälä, 2008). Professional knowledge also consists of self-regulative knowledge that includes self-reflection and metacognition, and further of social-cultural knowledge which shows insight in prescribed conditions and procedures in the given context. In developing professional knowledge, the interaction between and integration of theoretical and practical knowledge is essential (Eraut, 2004, 2012; Lave, 2009; Tynjälä et al., 2014). Therefore, many vocational courses embraced the concept of competence-based curricula, wherein knowledge, skills and attitudes are offered in an integrated way, so that knowledge is better transferred, and norms, values, and motivations become more central in professional learning (Van Merriënboer \& Kirschner, 2018). Competence-based learning is based on constructivist learning theories. The main features are that learners a) construct their own understanding and knowledge of the world b) through experiential learning situated in authentic contexts c) by discovery learning, self-directed learning and reflecting on those experiences in dialogue with others (Simons et al., 2000). Particularly learning in authentic contexts by active, self-directed learning is assumed to help students to make the transition from education to practice (Lave, 2009; Tynjälä, 2008). Accordingly, the teacher's role has changed from a provider of answers to the role of a coach to recognize and correct misconceptions of students as early as possible so that professionals will build a correct knowledge network (Van Merriënboer \& Kirschner, 2018). Students in the human professions need an extended knowledge network to meet the needs in the ill-structured domain. However, in domains like Social Work doubts arose whether students were building a correct knowledge network. To what extent did their quantitative and qualitative knowledge building benefit from the effects of learning in authentic contexts and by active, self-directed learning in a competence-based curriculum? An extensive study was conducted (Van Bommel et al., 2012a, b). Results suggested that the situated way of learning placed too much emphasis on the instrumental use of knowledge and that self-directed learning was too demanding for these students. The majority of students needed more learning support than offered in their program. The Dutch nursing association 'Nurses and Professional Caregivers' recognised similar problems in their domain and commissioned the development of a new national competence-based training profile for bachelor nursing students (Lambregts et al., 2016). Following up on these developments, the aim of the current research was to explore Bachelor Nursing (BN) students' experiences in 
learning during their new developed competence-based curriculum in respect to the main ingredients in constructivist learning: self-directed learning and learning in authentic contexts. The central research question is to what extent the qualitative characteristics of professional knowledge of Bachelor Nursing students meet the requirements for qualification as a new professional $\mathrm{BN}$, and what their experiences with learning are in the new developed competence-based curriculum, specifically with respect to self-directed learning and learning in authentic contexts.

\section{Theoretical Background}

\section{Theory-Practice Gap}

Since decades, nursing education struggles with a persistent gap between the theoretical knowledge that students gain in the study program and the application of this knowledge in professional practice. This gap becomes especially visible in situations in which the mainly explicit and formalized knowledge is called upon and the novice nurses ${ }^{1}$ fail to recontextualize this knowledge in acute practical situations (Smeby \& Vågan, 2008). Searching for a reason for the gap, Bendall (1976) and Kramer (1974) suggest that the professional knowledge in the education programs is apparently independent of the knowledge that is required in practice to be able to act as a full member of the profession. Benner (1984) explains that the theory-practice gap exists because nurses need further training in practice to achieve an excellent level of professional knowledge (Benner, 1984; Benner et al., 2010). Other researchers advise to bridge the gap by changing the content of education programs, because clear disparities have been demonstrated between the holistic approach, the best practice ideals, and values that students learn and what they actually encounter in a rule-based and outcome-based everyday practice (Hickman et al., 2018; Maben et al., 2006; Murray et al., 2018). Furthermore, the perception of knowledge development has changed in society and professions by the prevailing paradigm of the evidence-based practice. Professionals in twenty-first century are expected to quickly search the needed knowledge, but in professional practice concerns arose about novice nurses' knowledge base needed for recognizing patients' problems in practice and problem-solving skills (Lave, 2009; Tynjälä, 2008). Many newly graduated nurses follow trainee programs ranging from six months to one year to gain more experiential knowledge before becoming a full member of professional practice (Hatlevik, 2012; Ten Hoeve et al., 2017).

\section{Developing Professional Knowledge}

From the point of view of instructional design, education should provide a complete and well-organized supply of knowledge to avoid a gap between the theory that is offered in the training program and the knowledge that is needed for adequate practice that allows independent professional action in nursing practice as well as further development toward higher levels of expertise (Bereiter, 2002; Boshuizen, 2003;

\footnotetext{
${ }^{1}$ We use the term novice or novice nurse to refer to new entrants in the profession who have recently graduated.
} 
Tynjälä, 2008). One of the solutions is a competence-based curriculum, wherein knowledge, skills and attitudes are integrated (Van Merriënboer et al., 2002). Yet, Hatlevik (2012) and Ten Hoeve et al. (2017) found that many nursing students in competence-based curricula missed coherence between theory learned at school and its use in nursing practice. Hatlevik (2012) and Tynjälä (2008) both claim that many bachelor students lag behind in the development of professional behaviour because they do not or rarely reflect on how they can link theoretical concepts to the knowledge they acquire by experiential learning in professional practice. Essential for professional knowledge development is that explicit theoretical knowledge and implicit experiential knowledge come together, and that formal and informal knowledge integrate. A deep integration of theoretical, practical and self-regulatory knowledge in a certain sociocultural context is an important step toward expertise (Benner, 1984; Boshuizen, 2003; Elvira et al., 2017; Tynjälä, 2008). The same integrated knowledge base is an important condition to build higher levels of expertise after entering the workforce (Boshuizen et al., 2020), where new entrants may suffer a delay (Gijselaers et al., 2006). The question is, however, whether that is really happening in competence-based education, for all students - the good and the weaker ones - and for all topics at a level deemed necessary for a successful start as a novice, and whether such a curriculum is indeed implemented as intended (Montecinos et al., 2011).

\section{Improving Knowledge Quality}

The intended curriculum in professional nursing education is the curriculum based on the ideas of managers in practice and education (Montecinos et al., 2011, Valcke, 2017). Kessels (1999) points out that the consistence between the ideal and the achieved curriculum should be as great as possible. He indicates that external consistency in curriculum development should be achieved between managers, developers, trainers and trainees (the stakeholders) of what problem has to be resolved and how this would be accomplished. Further, internal consistence is reflected in how instructional strategies, materials and learning environment are deployed. Internal consistency can be disturbed by the perception of the teachers of how the curriculum is operationalized in instruction activities. Tynjälä et al. (2014) dived deeper into the micro-dynamics of these learning processes for an optimal achieved curriculum and developed the model of integrative pedagogy, see Fig. 1. The model emphasises the importance of the integration of different knowledge bases (conceptual theoretical, practical experiential, self-regulative, and sociocultural knowledge). These knowledge bases are often learned in different contexts in professional and vocation learning settings and curricula; processes of reflection and transformation are required to reach a strong, sustainable knowledge base (Ohlsson, 2011).

The arrows between conceptual/theoretical and practical/experiential knowledge illustrate the transformation, explication, and conceptualization of these two components. Students should be encouraged to use concepts, principles and models in their reflection on experiences in practice. Doing this will deepen the understanding of professional knowledge and students will reach a more abstract level in their thinking (Tynjälä et al., 2014). The self-regulative knowledge component in the model represents the system of conscious management of one's own thoughts, behaviours and feelings to achieve the learning goals (Bereiter \& Scardamalia, 1993; Jossberger et al., 


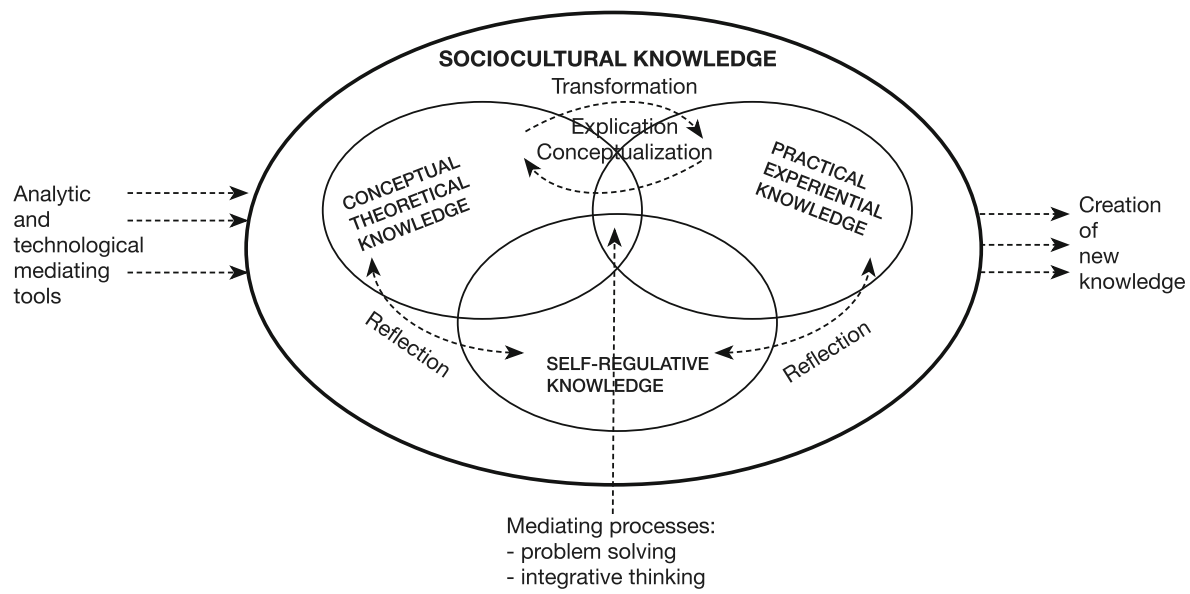

Fig. 1 The model of integrative pedagogy. Adapted from "TEL@work: Toward integration of theory and practice," by P. Tynjälä et al., 2014, British Journal of Educational Technology 45(6), p. 993. Copyright Tynjälä et al., 2006 by P. Tynjälä

2018; Zimmerman \& Schunk, 2011). Analytic and technological mediating tools like writing, discussions, and coaching are needed to make connections between the different forms of knowledge to create new knowledge. The fourth component in the model, socio-cultural knowledge, is important to understand the context with its implicit rules. Students will optimally learn these components through participation and reflection on their acting in professional practice (Virtanen et al., 2014; Wenger, 1998). To make it practical: nursing students learn anatomy, physiology, and pathology in education, and nursing activities are geared to medical treatments. Student also learn communication skills to deal with anxious people. But the application of this skill, dealing with anxious people, can vary enormously with different patients in various contexts in which nurses are working. By reflecting on the available knowledge, their own way of acting in that situation and the experience of successful action, students expand their action repertoire. However, whether this ideal situation emerges depends on the interplay between curriculum, students, teachers and professional practice; both virtuous and vicious learning cycles can develop.

As mentioned before, Van Bommel et al. (2012a, b) conducted research to appraise last year students' theoretical knowledge qualities after having attended a constructivist social work program in a Dutch university of applied sciences. They found indications that the curriculum worked out differently for different students. Only a quarter of the participants developed instrumental knowledge, i.e., knowing what to do, and knowledge as a system of meaning, i.e., knowing why and how, needed for proper professional practice and development of this practice (Wheelahan, 2010). The similarities between the domains of social work and nursing are large. Students learn to combine theoretical knowledge, practical skills and a professional attitude that is required for initial qualification (bachelor level), allowing them to solve complex caring problems and dilemmas. The domains also share the role of scientific evidence, and the use of psychosocial and communication skills. Therefore, we used the instruments by Van Bommel et al. (2012a, b) to investigate our research questions 1) How do final year BN 
students describe their experiences with self-directed learning in authentic contexts in the competence-based curriculum and how do students differ? 2) What are the qualitative features (critical control, extent, depth and structure) of their professional knowledge and how do students differ? 3) To what extent do the qualitative characteristics of the professional knowledge of the students meet the requirements for qualification as a new professional $\mathrm{BN}$ ?

\section{Research Setting}

$\mathrm{BN}$ education in the Netherlands lasts four year in universities of applied sciences. The training includes $2300 \mathrm{~h}$ of learning in nursing practice, prescribed by law. Despite the development of a new Dutch national education program of BN (Lambregts et al., 2016), traineeship of six months to one year is still offered to novices in practice.

\section{Method}

The present study was designed as an instrumental multiple case study, where the case is used as a comparative point across other cases in which the phenomenon is also present. The particular phenomenon in this study was the quality of the individual BN professional knowledge base at the end of the formal education program and the teaching and learning that led to it. Triangulation of research methods, semistructured interviews departing from an own experience, concept mapping and filling out a body of knowledge form, was used to gain more reliable and valid insight in the theme under research (Creswell, 2014; Flick, 2004). These different methods allow different views on the phenomenon investigated: knowledge learning, use, structure, and recognition. Quantification of qualitative data from the interviews was included in the analysis (Chi, 1997). Inductive and deductive approaches were combined (Miles \& Huberman, 1994) to access students' experiences in learning and assessing the quality of their professional knowledge. To provide more insight into the research process, Table 1 presents the three research questions with the methods of data collection and data-analysis.

\section{Participants}

A representative reflection of the population in this sample was obtained by inviting students with the highest and lowest grade average for their passed tests in their final year in a BN education program. The secretary of the examination board selected students until the required number was obtained. In total, 12 female and 2 male fulltime students, and 2 female part-time students were recruted, all learning in the same curriculum. The participants varied in age from 20 to 24 years, one was aged between 50 and 54. The full-time students had attended general secondary education, the parttime students earlier graduated from secondary vocational education in nursing. Half of the participants had high grade averages $(M=7.7)$, the other part had lower grade averages $(M=7.3)$, with achievable grades between 6 to 10 for passed tests. The 
Table 1 The mutual coherence in research questions, instruments, data collection and data analysis

\begin{tabular}{|c|c|c|}
\hline Research question & Instruments \& data collection & Data-analysis step 1-4 \\
\hline $\begin{array}{l}\text { 1. How do final year BN students } \\
\text { describe their learning } \\
\text { experiences in with self-directed } \\
\text { learning in authentic contexts in } \\
\text { the competence-based curricu- } \\
\text { lum and how do students differ? }\end{array}$ & $\begin{array}{l}\text { Topic list: semi-structured } \\
\text { interviews based on the } \\
\text { individual submitted case, } \\
\text { added with texts of the think } \\
\text { aloud procedure during the } \\
\text { concept mapping task }(n=16) \text {. } \\
\text { Body of Knowledge BN2020: } \\
\text { filling out a list with items. }\end{array}$ & $\begin{array}{l}1 \text { Thematic analysis of learning } \\
\text { experiences in authentic } \\
\text { contexts and with self-directed } \\
\text { learning in } 16 \text { transcripts with } \\
\text { digital program Atlas.ti 8.0. } \\
\text { A bar chart generated in Excel. }\end{array}$ \\
\hline $\begin{array}{l}\text { 2. What are the qualitative features } \\
\text { (critical control, extent, depth } \\
\text { and structure) of their } \\
\text { professional knowledge and } \\
\text { how do students differ? }\end{array}$ & $\begin{array}{l}\text { Drawing concept maps: concept } \\
\text { maps of patients' cases }(n=16) \text {. } \\
\text { Compile a code list based on the } \\
\text { instrument 'Criteria for } \\
\text { qualitative assessment of } \\
\text { knowledge aspects' in Atlas.ti } \\
8.0 \text {. } \\
\text { Scores on the code list were } \\
\text { entered in SPSS. }\end{array}$ & $\begin{array}{l}\text { 2a Analysis of conceptmaps for the } \\
\text { feature structure of professional } \\
\text { knowledge. } \\
\text { 2b Analysis of the } 16 \text { transcripts } \\
\text { with the code list in Excel to } \\
\text { calculate participants' individual } \\
\text { scores per knowledge aspect and } \\
\text { feature, presented in bar charts. } \\
3 \text { A correlation table in SPSS } 25.0 \text {. }\end{array}$ \\
\hline $\begin{array}{l}\text { 3. To what extent are the qualitative } \\
\text { characteristics of the } \\
\text { professional knowledge of the } \\
\text { students to meet the } \\
\text { requirements for qualification as } \\
\text { a new professional BN? }\end{array}$ & $\begin{array}{l}16 \text { completed lists of the Body of } \\
\text { Knowledge BN2020. }\end{array}$ & $\begin{array}{l}4 \text { Analysis of scores on list BOK } \\
\text { BN2020 in Excel presented with } \\
\text { a bar chart and after that } \\
\text { comparison with the obtained } \\
\text { individual qualitative features of } \\
\text { professional knowledge. }\end{array}$ \\
\hline
\end{tabular}

weighted high and low averages were close to each other as the mark for a successfully completed internship was 7 or 8 in the Dutch system, and the internship was a significant part of the training. Participants had more than one year of work experience in the healthcare sector due to internships and part time jobs. The participants in this multiple case study represented the general features of the total final year BN students population $(N=146)$ like gender, age, and working experience.

\section{Instruments}

In total three instruments were used to elicit BN student's professional knowledge and to discover experiences in learning in a competence-based curriculum, to assess qualitative features of their knowledge, and to determine the degree of agreement with requirements of their professional knowledge. For the semi-structured interviews an interview guideline, based on the literature review, was developed to capture the student's application of theoretical knowledge and learning experiences in practice (Creswell, 2014). The first question was to present a critical incident. That is, to describe an individual patient situation they have experienced as quite challenging in their internship or at their side job.

Further interview questions, derived from a literature study on domain knowledge of nurses, regarded the knowledge quality that is needed in nursing professional practice 
according to the participants, see Appendix. The second instrument was a concept mapping task of the presented case.

Such maps can effectively represent understanding of the domain, organization of the concepts, and relationships between the concepts (Novak \& Cañas, 2008; Riemer \& Schrader, 2016). The third instrument was the domain knowledge list "Body of Knowledge Bachelor Nursing 2020" (BOK BN2020). The core concepts on this list were derived from the nursing education program (Lambregts et al., 2016, pp. 74-82). Participants could answer if the items were recognized as worked-through theory with "yes", "?" or "no". The answers provided an indication of which study material of the lessons the students considered to be known, not exactly known or unknown. The current instrument was pilot-tested by five nursing experts at the university, and found to be complete and reliable.

\section{Procedure Data Collection}

Participants who agreed to participate in the research signed the informed consent letter with information about data integrity and how privacy of participants would be protected. They received a short instruction by email to prepare a case that they had experienced in practice and in which they had felt challenged. At the start of the interview, participants explained their prepared case and reflected on how nursing care was provided. Based on the interview guideline, the researcher monitored that in every interview the topics 'experiences in learning with the curriculum' and 'gaining professional knowledge' were illuminated. Each participant also got a short instruction by email on drawing a concept map, meanwhile thinking aloud (Ericsson \& Simon, 1998). Next, the "BOK BN2020" was presented with a short explanation that this list was part of their Bachelor Nursing education profile; students were asked to fill in to what extent they recognized the items, again thinking aloud. The audio recordings of the entire conversations were elaborated into transcripts.

\section{Data Analysis}

As outlined in Table 1, four steps were used to ensure the quality of the data analysis process. The iterative process in the analysis of the data made it possible to make statements about the mutual coherence of the various components in this instrumental multiple case study (Creswell, 2014).

In the first step each transcript of the combined interview and the think aloud task while drawing a concept map and filling in the list "BOK BN2020" was analysed in the digital program Atlas-ti 8.0. With the method of thematic analysis transcripts were divided into text segments. The text segments were given open codes and thereafter codes were collapsed into broad themes, called axial coding. This inductive process of narrowing data has been continued until selective codes, the themes, appeared related to learning experiences, authentic contexts and self-directed learning (Brown \& Clarke, 2006; Creswell, 2014).

In step two we investigated and scored the knowledge qualities with respect to the outcomes. We used the validated instrument "Criteria for scoring knowledge aspects at initial qualification at bachelor's level and the knowledge features they 
represent" of Van Bommel et al. (2012a) to assess the qualities of the knowledge the participants expressed in in the interviews and concept maps. This instrument was based on the four features of expert knowledge (critical control, extent, depth, and structure) and the corresponding aspects of knowledge quality, see Fig. 2.

The first feature of expert knowledge, critical control, reflected the use of formal professional language and number of concepts explicitly mentioned versus informal, concrete-only language. The second feature, extent of knowledge, overlapped partly with critical control and was reflected in the use of explicit concepts and in unarticulated knowledge which were not explicitly mentioned, but indirect recognizable in described actions and deliberations. Further, extent was derived from the situational and contextual facts mentioned in the narratives. For both extent and depth, the professional relevance of narrative-elements and the completeness of the narrative expressed in all elements was essential for a professional description of the case. Depth of knowledge was reflected in the number of work levels (personal, organizational and societal) and the connections made between these levels in the narrative. Accounting for actions gave an impression of the number of concepts and how much was known about it. Viewpoints referred to the inclusion of viewpoints of different actors or work levels and role awareness to the awareness and handling of one's own professional role in connection to interprofessional collaboration and contextual circumstances. Structure of knowledge was appraised in the concept mapping task, where analytical perspective was about depicting and explaining the case and own actions, complexity was the number of relevant elements and work levels plus connections on the map, and completeness of structure the completeness of all essential elements in the concept map. Selected phrases were appraised on a 3-point scale for each aspect.

The instrument had been developed for appraising professional knowledge of bachelor students Social Work. Because BN students applied more explicit concepts in their interviews, one aspect on the instrument, criteria for the number of "explicit concepts", had to be adjusted. Based on the median of 64

\begin{tabular}{|c|c|c|}
\hline \multicolumn{2}{|c|}{ Features of expert knowledge } & Aspects of knowledge quality \\
\hline \multirow{6}{*}{ Extent } & \multirow{2}{*}{ Critical control } & Professional language \\
\hline & & Explicit concepts \\
\hline & & Unarticulated knowledge \\
\hline & & Situational facts \\
\hline & \multirow{6}{*}{ Depth } & Professional relevance \\
\hline & & Completeness of narrative \\
\hline & & Work levels \\
\hline & & Accounting for actions \\
\hline & & Viewpoints \\
\hline & & Role awareness \\
\hline & \multirow{3}{*}{ Structure } & Analytical perspective \\
\hline & & Complexity \\
\hline & & Completeness of structure \\
\hline
\end{tabular}

Fig. 2 Aspects of knowledge quality and their relation to the four features of expert knowledge. Adapted from "Appraising the qualities of social work students' theoretical knowledge: A qualitative exploration." by Van Bommel et al., 2012a, b. Vocations and Learning, 5(8), p. 286. Copyright 2012 M. van Bommel 
concepts in the transcripts, one point was given when 40-59 concepts were counted, two points for 60-69 concepts, and three points for 70-90 concepts. The instrument was entered as a code list in Atlas.ti 8.0. Following the descriptions on the code list, text segments and structure features were appraised with three points when the student expressed connections between various professional concepts and presented a logical description of own nursing actions. Two points were given when knowledge was expressed in more or less connected professional concepts, not always presented in a logical way. One point was given for the use of professional knowledge when a participant used inconsistent knowledge and when concepts were misused. The code list was applied independently by a second coder, the interrater reliability Cohen's Kappa was "moderate": $k=.53$ (Landis \& Koch, 1977). In consultation with the second author, the coders made new agreements on how the instrument should be interpreted. Next, the first author $(\mathrm{RdH})$ coded all segments, constantly checking for internal consistence. The appraisals of the three aspects of structure were derived from the concept maps and added in Atlas.ti. Then the appraisals for each aspect of knowledge quality were transported to Excel after which a qualitative profile of each student's professional knowledge was composed based on an equal distribution with the values High (3.0-2.4), Medium (2.31.7), and Low (1.6-1.0), allowing cross-case analysis. Subsequently, average scores were also calculated for the four knowledge features, extent, depth, structure, and critical control. The individual participants were rank-ordered based on the means of the 13 underlying aspects, and indicated by the code of their mean scores - H, M or L - followed by their place in the ranking, e.g., "H2" or "M5". Following the characterization of Van Bommel et al. (2012b), Mparticipants with two or more $\mathrm{H}$-appraisals on the four characteristics of expert knowledge have been designated as HM-participants to distinguish them from lower scoring M-participants.

In the third step Spearman's correlation coefficients were computed in SPSS 25.0 to explore correlations between students' appraisals on the 13 knowledge aspects as well as between these appraisals and three student attributes: prior education, grade point averages, and work experiences.

In step four the participants' responses on the "BOK BN2020" were analysed in Excel; a bar graph was compiled to detect to what extent categories of the Body of Knowledge in BN education were recognized by the participants. After the analysis, member checking was offered to the students to find out to what extent the results obtained were recognized (Creswell, 2014), only three students volunteered and they agreed.

\section{Results}

A total of $16 \mathrm{BN}$ students (14 female, 2 male) took part in this research, being representative for the student population in this study program. The complete task of the interview, the concept mapping task and filling in the list "BOK BN2020", lasted 100-120 min per participant. Results are presented in the next four 
paragraphs: BN students' experiences in learning, Appraising knowledge qualities, Knowledge aspects and correlations, and List Body of Knowledge BN2020.

\section{BN Students' Experiences in Learning}

The first research sub question was how do final year BN students describe their experiences with self-directed learning in authentic contexts in the competence-based curriculum and how do students differ.

\section{Learning Nursing Knowledge}

Final year BN students liked to reflect on their experiences in learning in the competence-based curriculum with self-directed learning in authentic contexts. All participants were convinced of their initial choice for nursing education and found the subject matter on anatomy, physiology and medicine as "very interesting"; higher scoring participants also found these topics "informative and super useful". The lessons nursing skills in year 1 and 2 were also much appreciated. "This is what nursing is about!" (Participant M5). Some participants regretted that these lessons were only in the first two years of the program "because at that moment you cannot practice it, these lessons are needed in year 3 and 4 in your internship." (L2). Most participants indicated that learning was not always driven by their interest, but more by the tests they had to pass. The huge number of tests was often a problem: "I wanted to know everything, revised it, took the test and then deleted [knowledge] to go on to the next semester. I wonder to what extent I really know what I have learned." (M7). Because of the large amount of theoretical material, participants felt they had to learn for the tests, they were not always able to "recall concept lists", but at crucial moments "It was cool that I could explain the diabetes disease and how it works to the patient." (H1).

M-participants indicated that they were very interested in the lessons, but "soon after an exam I needed to clear my mind for new knowledge." (M6). L-participants were satisfied if they had passed the test "then the theory could be forgotten." L2 added: "During the test the knowledge is available in my head, but what do I have to do with it afterwards? I delete." Some H- and M-participants regretted that so much attention was paid in education to cramming large quantities of knowledge. They would have preferred more repetition and deepening to be better trained in applying knowledge. "Clinical reasoning is so cool because it is different for every patient. Why was no more attention paid to it at the university? Now I really had to learn it in practice." (M5). The participants were also less enthusiastic about the law and ethics lectures in the first years in education, because it was a lot of information, and was of little practical significance for them. "Why five, six lectures on laws when it could have been done in one lesson or I can read it myself?" (M5). And M8: "I have not attended classes in ethics, it was sufficient to learn the PowerPoints and I received high marks."

\section{Authentic Contexts}

Theory and skills learned in the lessons professional communication were considered important. Students indicated that learning supported with written lifelike cases situated in authentic contexts was instructive in the beginning, but later they experienced the cases 
as "physically focused" and "not very creative and challenging, because cases were identical in several lessons." (H1, M8). The participants missed the holistic approach toward patients and clients they had been trained on from the start of the education. For some participants role-playing in the classroom based on the written cases was not realistic and sometimes a "nightmare". They felt embarrassed to pretend and were disappointed that no alternative instructional methods were used. "You can better learn it in practice." (M8). L1 stated that learning from written cases was not effective, because "you have to learn to feel what you have to do in practice, this does not work." The participants were happy with teachers who were still working in practice and told stories about their patients or clients. "I liked his stories, I wanted to go and see it myself' (M4). All participants thought that they had learned more during the internships than at the university, because "if you have to apply knowledge yourself, it will stick more easily." (M8). Not all internships went well, some students missed skills to reflect on their learning (M2, M6, L2) and had less attention for learning to apply theoretical knowledge.

\section{Self-Directed Learning}

The H- and HM-participants felt challenged to discover more about medical diagnoses unknown to them or about recent theoretical and practice development in the field of nursing. They themselves were working on it apart from the learning assignments. These participants indicated that they had learned how to look for reliable information sources during their study, the twenty-first century skills. "I really wanted to know, because I felt responsible for the health of another person!" (M2). Almost all participants shared the frustration about their internship that was completed with a written paper; it was described as "an assignment without instructions". This made them uncertain whether they had carried out the assignment adequately. H3: "I would have liked more guidance, it did not feel comfortable to sort out everything myself." Many Mparticipants mentioned their effort for learning to work in practice and simultaneously learning to apply theoretical knowledge "for school", looking to it as two different things. Five participants remarked that they were not sufficiently challenged in the theoretical program. "I started to make my homework on Monday morning and that was it for the rest of the week. I felt disappointed about the program!" (HM2). HM2 and M5 asked the teacher how they could deepen their learning, but were reminded to choose study objects themselves. "How do I know where to look? I wanted to quit the training for nursing, but had no alternative at that time." (M6). M- and L-participants liked to work in peer groups, but the $\mathrm{H}$ - and some M-participants experienced working on assignments with peers as delaying (M4, M8). They found the course of affairs in the lessons "monotonous". "First a homework assignment, further sharing via e-mail and then a discussion on the same work in the class. It often came down to the fact that at least half of the students had not prepared [...] so I did not share my answers anymore." (HM2). On the other hand, L2 was glad to pick up the answers in class: "Regularly I couldn't find all answers and it would take as twice as long time to work on it." Most Mand L-participants expected that the teacher checked the "right answers", but that did not happen. 


\section{Appraising Knowledge Qualities}

The second research sub question was what the qualitative features (critical control, extent, depth and structure) are of students' professional knowledge and how students differ.

\section{Concept Mapping Task}

Structure of knowledge was appraised in the participant's concept map. Two Hparticipants and one M-participant hesitated a few minutes about how they could use theoretical models when drawing the concept map, but they finished the concept map with a logical summary of the case discussed. While concept mapping, all participants referred to some methodical models that they had learned earlier in the training. Various participants used the methodology of Gordon (2004) for making an anamnesis of nursing problems, or the vision on human functioning in the Neuman Systems Model (Verberk \& Merks, 2016). H1 made a concept map of a lady in her late sixties, who had been suffering from diabetes mellitus for over 30 years and was insulin dependent, see Fig. 3.

Creating the concept map, the holistic view in healthcare was chosen by starting in the middle with a post-it for Mrs. D. and post-its with physical elements right on the top. The participant wanted to include socially and psychologically oriented post-its but got entangled in the layout. Then continued with the model of International Classification of Functioning (WHO 2001), but noted that the postits about the financial circumstances of Mrs. D. did not fit well with the model. She removed all post-its and started to regroup according to the Neuman Systems Model. Halfway through, she decided that Gordon's methodology would fit best, but struggled with the post-its of the other disciplines and stuck them in the middle together with home care. She was satisfied that the situation had been

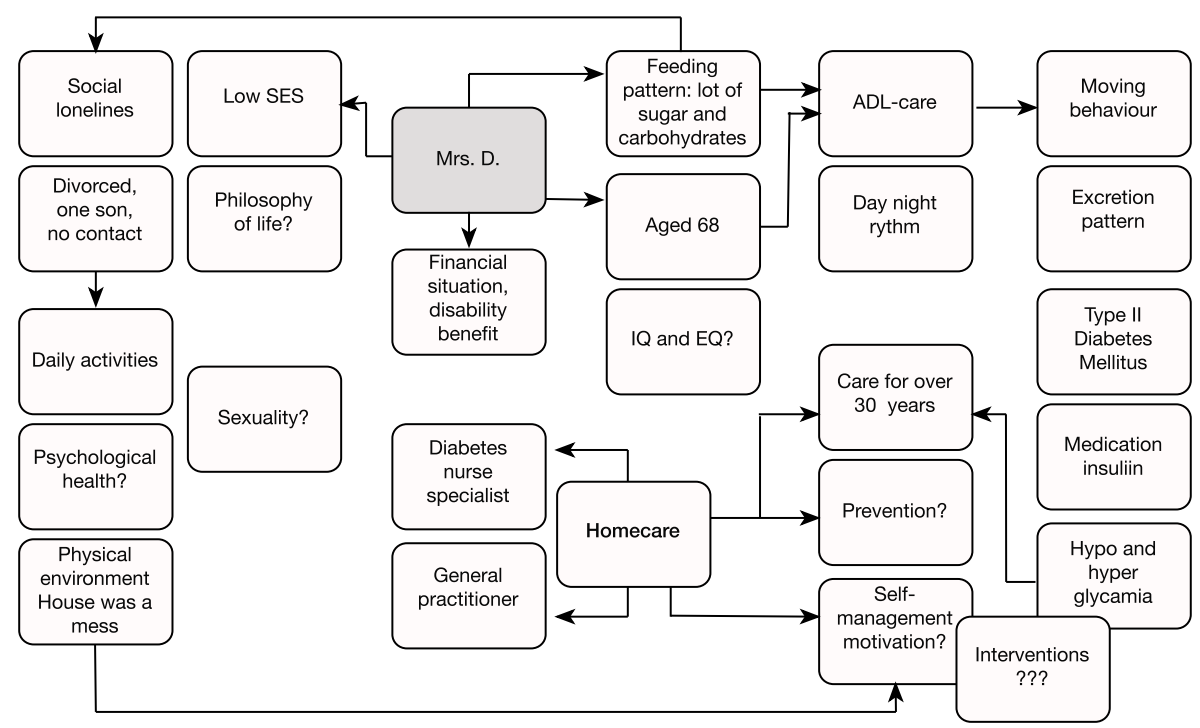

Fig. 3 Concept map of participant H1, showing different aspects in the case and how they are connected 


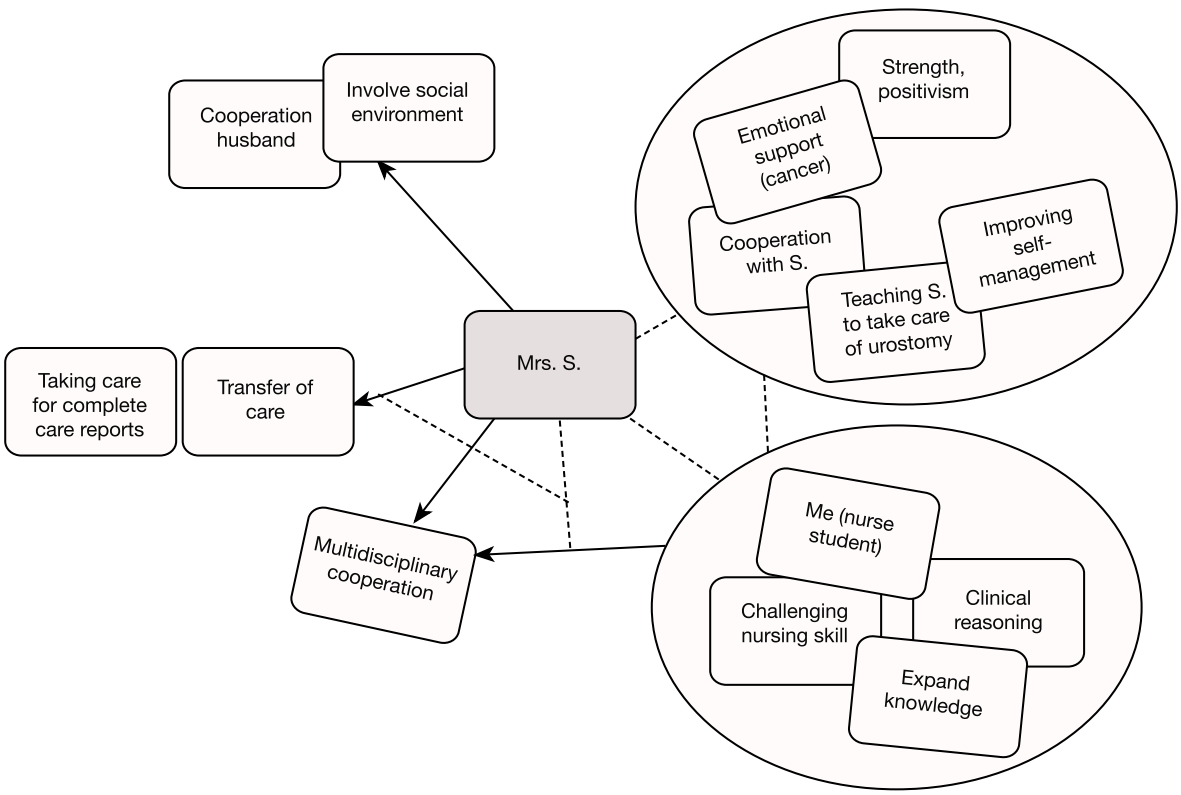

Fig. 4 Concept map of participant M7: approached from "tasks to shape care to S. and tasks for myself" (circles)

properly mapped. The patient and her context were recognized, including the question how to continue care in the future. In Fig. 4, M7 drew a concept map and pointed out her tasks in the primary care process just from the own perspective. This participant described the situation rather instrumental (describing what to do) and did not mention how this patient would feel in this situation. Because of the action-focus, an M-appraisal was given. At the start of the assignment, L1

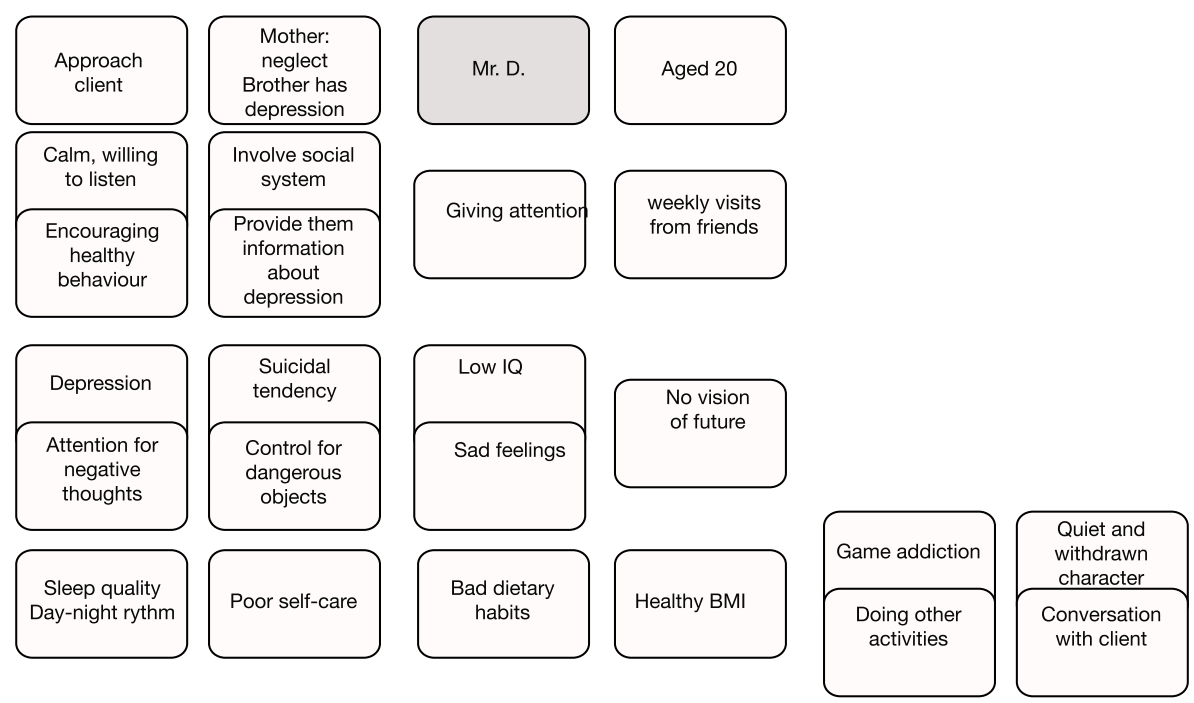

Fig. 5 Concept map of participant L1: connections between post-its were not established and in thinking aloud no nursing activity has been discussed 
immediately opted for a clinical reasoning method of six steps, but finished at step 2. L1 outlined the situation of a client without any connections between the postits despite repeated invitations by the interviewer. A professional nursing perspective on the organizational context or on how to act in this case is not included, therefore a low appraisal was given, see Fig. 5.

\section{Individual student's Profiles}

The next result in this research consisted of individual profiles of student's professional knowledge applied in the real-life context. The individual averages over the 13 aspects of knowledge quality were established per aspect and subsequently per characteristic. For the averages for the four features of knowledge (critical control, size, depth and structure), see Table 2.

In the first column the participants are divided into four groups, based on their total averages in each aspect of expert knowledge (second column): High (H), High-Medium (HM), Medium (M), and Low (L) appraisals. The H-participants $(n=3)$ received high appraisals with an average over 2.4. The HM-participants $(n=3)$ received high and medium appraisals with an average around 2.3. The M-participants $(n=8)$ got medium appraisals $(2.0-2.2)$ and the L-participants $(n=2)$ mainly low appraisals $(1.3-1.6)$.

Students' averages are fairly constant across the knowledge features, yet, there are some noticeable deviations. The appraisals for the knowledge qualities of M5 (who had

Table 2 Average scores of 16 participants on the four features of expert knowledge and on the 13 underlying knowledge aspects, and their $H$-, $H M-, M$-, and L-appraisals.

\begin{tabular}{|c|c|c|c|c|c|}
\hline $\begin{array}{c}\text { Students' } \\
\text { knowledge } \\
\text { assessment }\end{array}$ & $\begin{array}{c}\text { Knowledge } \\
\text { aspects }\end{array}$ & $\begin{array}{c}\text { Critical } \\
\text { control }\end{array}$ & Extent & Depth & Structure \\
\hline H1 & 2.72 & 3.0 & 2.8 & 2.7 & 2.7 \\
\hline H2 & 2.52 & 2.6 & 2.5 & 2.6 & 2.7 \\
\hline H3 & 2.47 & 2.8 & 2.7 & 2.2 & 2.7 \\
\hline HM1 & 2.31 & 2.5 & 2.5 & 2.5 & 2.0 \\
\hline HM2 & 2.30 & 2.2 & 2.3 & 2.4 & 2.3 \\
\hline HM3 & 2.28 & 2.0 & 2.3 & 2.4 & 2.3 \\
\hline M1 & 2.22 & 1.9 & 1.9 & 2.3 & 2.3 \\
\hline M2 & 2.18 & 2.2 & 2.4 & 2.2 & 20 \\
\hline M3 & 2.12 & 2.2 & 2.2 & 2.2 & 2.0 \\
\hline M4 & 2.01 & 2.0 & 2.2 & 2.2 & 1.7 \\
\hline M5 & 1.96 & 1.5 & 1.7 & 1.9 & 2.3 \\
\hline M6 & 1.96 & 2.4 & 2.2 & 1.6 & 2.3 \\
\hline M7 & 1.91 & 1.5 & 1.8 & 2.1 & 1.7 \\
\hline M8 & 1.74 & 1.4 & 1.7 & 1.6 & 2.3 \\
\hline L1 & 1.58 & 1.7 & 1.6 & 1.6 & 1.7 \\
\hline L2 & 1.41 & 1.3 & 1.4 & 1.5 & 1.3 \\
\hline
\end{tabular}

Legend

\begin{tabular}{|l|l|}
\hline & H $2.4-3.0$ \\
\hline & M $1.7-2.3$ \\
\hline & L $1.0-1.6$ \\
\hline
\end{tabular}


followed pre-university education and had a high grade-point average in the study program) stand out. The feature critical control received an L-appraisal, because this participant presented the case on an abstract level, then sighed and expressed no need for further explanation. When asked about backgrounds of professional knowing, M5 got enthusiastic and explained how to start a new study in future, escaping the discussion about the case and despite the interventions of the interviewer. For extent and depth M5 received medium/low ratings for the same reason. For structure, reflected in the concept map, a high appraisal was given because of admittedly few concepts, but with effectively drawn arrows. The appraisal of the knowledge qualities of M6 also shows an irregular pattern. M6 previously graduated from a secondary vocational training for nursing, worked more than four years as a nurse and achieved a moderate grade point average in the training. The H-appraisal on critical control is striking, probably caused by their work experience. They received an L-appraisal on depth because the only work level mentioned in the entire case description was on micro/ patient level. M2 received an $\mathrm{H}$-appraisal for extent because this pre-university student mentioned many loose concepts as a signal of extended knowledge, but did not relate them to the described patient. With regard to depth, the M-appraisal of H3 stands out, who described the processes in the case step-by-step at the patient's level, but left the organizational environment underexposed.

\section{Knowledge Aspects and Correlations}

In addition to determining the individual student profiles we studied how the appraisals were distributed over the 13 aspects of knowledge quality.

Table 3 shows the cumulative frequencies for each knowledge aspect. With regard to extent, it was striking that no H-appraisal was awarded for "situational facts". An Happraisal could be received if participants mentioned the whole context of care: care recipient, care provider, the organization, and society. But when a narrower description of the context was asked in the aspect "completeness of narrative", ten H-appraisals have been achieved, the rest received M-appraisals. "Completeness of narrative" was

Table 3 Cumulative frequency distribution of $H, M$ and $L$ scores on each of the 13 aspects of knowledge quality and means on the four features of expert knowledge.
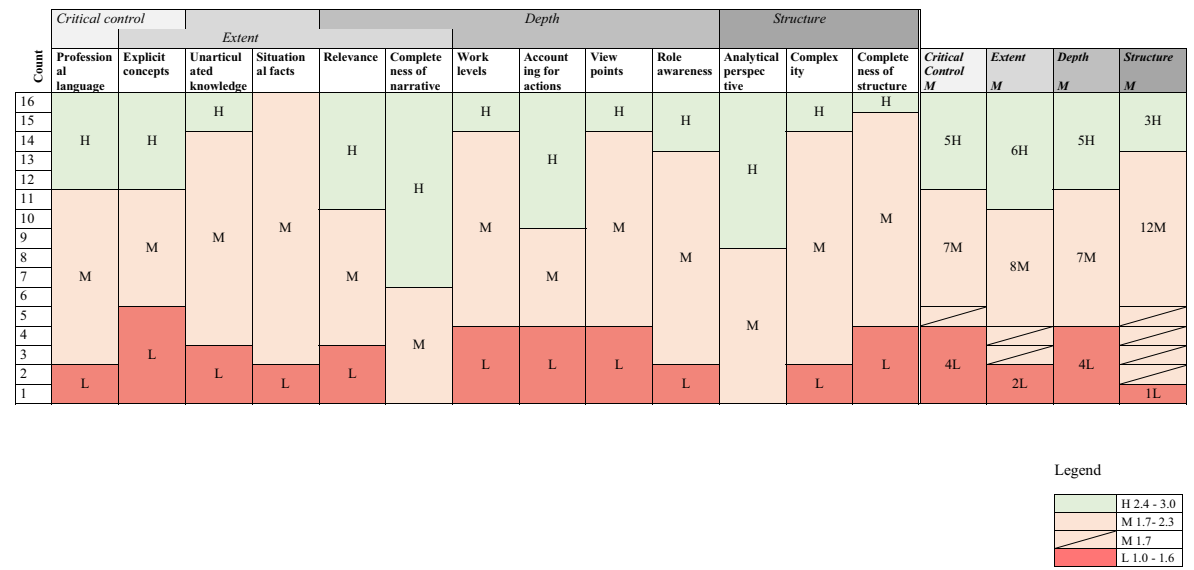
also part of the knowledge quality depth; it can be seen that seven H-appraisals have been achieved for "accounting for actions". For the feature structure, one H-appraisal and seven M-appraisals were given for "analytical perspective". The aspects of "complexity" and "completeness of structure" received mainly M-appraisals. For critical control, five times an H-appraisal have been achieved, several M-appraisals and two Lappraisal for "professional language" and five L-appraisals for "explicit concepts". The averages of the four overarching knowledge features were presented in the four right columns. Structure showed only one L-appraisal, but the four M-appraisals with a low average of 1.7 deserved attention.

\section{Correlations}

Table 4 shows that medium to high positive correlations were found between knowledge aspects belonging to the same knowledge features of expert knowledge: extent (aspect 2-6) ( $\mathrm{r}_{\mathrm{s}}$ between .5 and .8), depth (aspect 5-10) ( $\mathrm{r}_{\mathrm{s}}$ between .5 and .9) and structure (aspect 11-13) $\left(\mathrm{r}_{\mathrm{s}}=.5\right)$. The two aspects of critical control (1-2) did not

Table 4 Significant correlations (Spearman's $r_{\mathrm{s}}$ ) between the three student attributes $(A, B$, and C) and the 13 aspects of knowledge quality

\begin{tabular}{|c|c|c|c|c|c|c|c|c|c|c|c|c|c|c|c|}
\hline & A & B & $\mathrm{C}$ & 1 & 2 & 3 & 4 & 5 & 6 & 7 & 8 & 9 & 10 & $11 \quad 12$ & 213 \\
\hline \multicolumn{16}{|l|}{ A. Prior education } \\
\hline \multicolumn{16}{|l|}{$\begin{array}{l}\text { B. Grade points } \\
\text { averages }\end{array}$} \\
\hline \multicolumn{16}{|l|}{$\begin{array}{l}\text { C. Experience in } \\
\text { practice }\end{array}$} \\
\hline \multicolumn{16}{|l|}{$\begin{array}{l}\text { 1. Professional } \\
\text { Language }\end{array}$} \\
\hline \multicolumn{16}{|l|}{ 2. Explicit concepts } \\
\hline $\begin{array}{l}\text { 3. Unarticulated } \\
\text { knowledge }\end{array}$ & & & & $.7 * *$ & & & & & & & & & & & \\
\hline 4. Situational facts & & $.6 * *$ & & $.6^{* *}$ & $.6^{*}$ & $.6^{*}$ & & & & & & & & & \\
\hline $\begin{array}{l}\text { 5. Professional } \\
\text { relevance }\end{array}$ & & & & $.8^{* *}$ & $.6 *$ & $.5^{*}$ & $.8 * *$ & & & & & & & & \\
\hline $\begin{array}{l}\text { 6. Completeness of } \\
\text { narrative }\end{array}$ & & & & & & $.5^{*}$ & & & & & & & & & \\
\hline 7. Work levels & $.5 *$ & & & $.9 * *$ & & $.8 * *$ & & $.5^{*}$ & & & & & & & \\
\hline $\begin{array}{l}\text { 8. Accounting for } \\
\text { actions }\end{array}$ & & $.6^{*}$ & & & & & & & & & & & & & \\
\hline 9. Viewpoints & & & & & & & $.5^{*}$ & $.7 * *$ & $.7 * *$ & & & & & & \\
\hline 10. Role-awareness & & & & $.7^{* *}$ & & $.5^{*}$ & $.6^{*}$ & $.8 * *$ & & $.6 * *$ & & $.6 *$ & & & \\
\hline \multicolumn{16}{|l|}{$\begin{array}{l}\text { 11. Analytical } \\
\text { perspective }\end{array}$} \\
\hline 12. Complexity & & & & $.6^{*}$ & & & $.7 * *$ & $.7 * *$ & & & & $.5 *$ & $.5^{*}$ & $.5^{*}$ & \\
\hline 13. Completeness of & & & & $.5^{*}$ & & & & $.6^{*}$ & & & & & & & \\
\hline
\end{tabular}

$* p<.05 ; * * p<.01$ 
correlate significantly with each other, but "professional language" did show significant correlations with seven aspects $\left(r_{\mathrm{s}}\right.$ between .5 and .9). The highest correlation was found between "professional language" and "work levels" $\left(r_{\mathrm{s}}=.9, p<.001\right)$. No significant correlations were found between the student characteristics, although this was expected between prior education (A) and grade points average in the education (B). Prior education and "working levels" correlated moderately $\left(r_{\mathrm{s}}=.5, p<.005\right)$. The average grade in the degree program (B) correlated with "situational facts" and "accounting for action" $\left(r_{\mathrm{s}}=.6\right)$; no significant correlation was demonstrated between experience in practice $(\mathrm{C})$ and the 13 aspects of knowledge quality.

\section{List Body of Knowledge BN2020}

The third research sub question was to what extent the qualitative characteristics of the professional knowledge of the students do meet the requirements for qualification as a new professional BN.

While filling in the domain list "BOK BN2020" most participants confessed that they were not aware of the existence of a body of knowledge in nursing. Going through it, they were surprised about the amount of knowledge they apparently had learned. Answering the question if they would add something to their case, both an H- and Mparticipant recognized that they had missed to mention daily care in their interview. "Of course, I assisted with activities of daily living and I gave medication.” (H1). Others noted that the anamnesis was missing or that they could have mentioned multidisciplinary cooperation more explicitly. None of the participants wanted to add update their

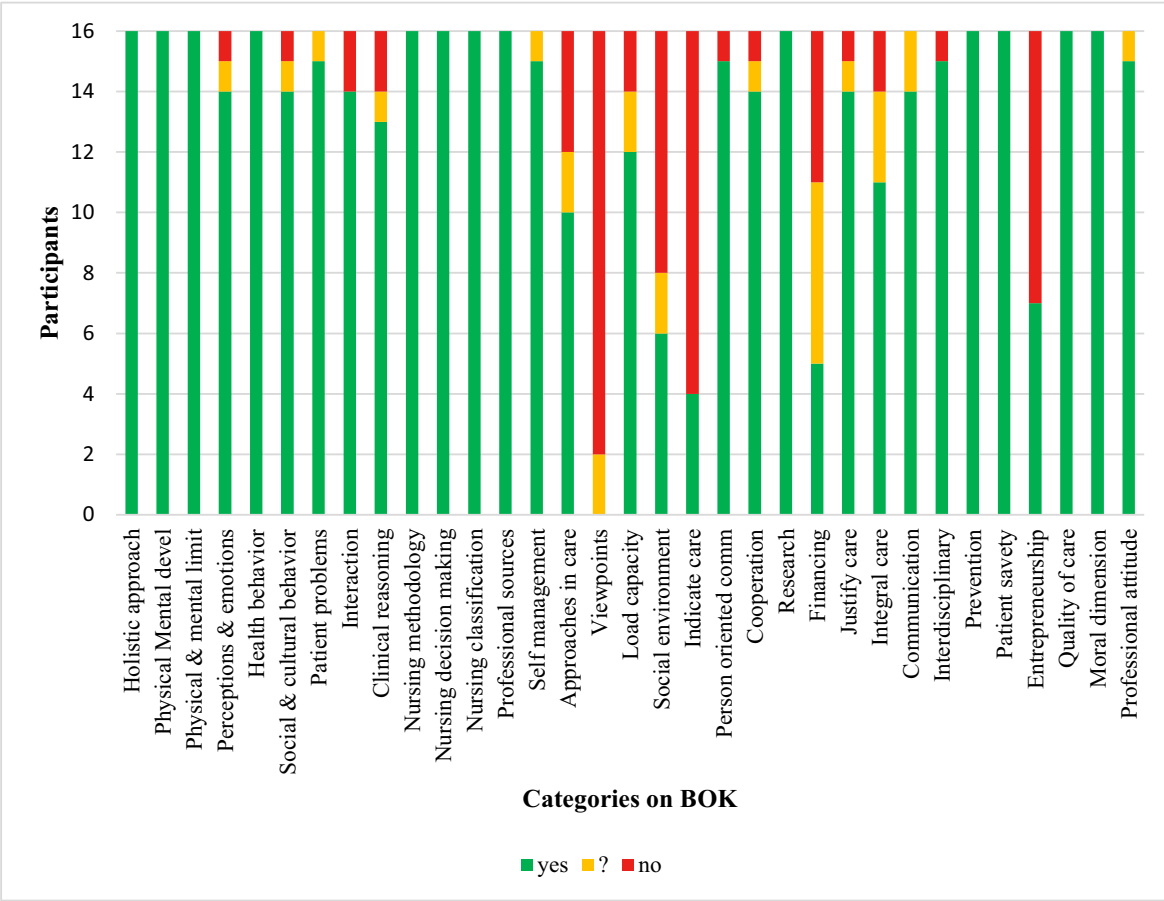

Fig. 6 Recognition of categories on the Body of Knowlegde BN2020 
case description nor in the concept map based on the Bok BN2020; they were satisfied with the given explanation. The scores showed that all participants recognized most of the first eight categories of knowledge of the primary care process. Categories of nursing theories were less familiar to them. The items on the last eleven categories, belonging to the organizational context of nursing care, were recognized, but participants hesitated if they have had lessons about the financial systems in care and how to take entrepreneurial action, see Fig. 6.

There were no striking differences between H-, HM-, M-, or L-participants. It could be observed that some H-participants enthusiastically recognized all knowledge categories and filled in the list quickly. Other H- and HM-participants argued if they would know enough to be successful in practice and hesitated if they could answer with "yes". Some low M-participants and one L-participant filled in the list with a rush, being sure that they recognized all categories. A comparison between the H- and HM-participants' lists and the M- and L-participants' lists showed that these two groups scored very similar. Almost all participants recognized the categories of the primary care process in the first part of the list. The last part, categories from the organizational context, were more or less common to them, except financing and entrepreneurship, which were more recently implemented topics. The participants had the most difficulties to recognize the categories between 'approaches in care' and 'research'. These were important elements of the foundations in nursing theories.

\section{Discussion}

This study was conducted to explore 1) the learning experiences of Bachelor Nursing (BN) in a competence-based curriculum, 2) the associated learning outcomes in terms of knowledge qualities, and 3) the extent to which these outcomes meet the requirements for qualification as a new professional BN. Students' learning experiences varied largely and so did the knowledge qualities they attained. In their learning experiences H- and HMparticipants were found to further develop their knowledge network and expand it during the internships. H-participants flourished in the education program with self-directed learning and appreciated teachers in the role of a coach. Doing so they succeeded in going through the different processes of learning professional knowledge as described by Tynjälä (2008) (Fig. 1). M-participants were also interested to learn a lot of theoretical knowledge, but used superficial learning strategies that resulted in a fast decay. The Lparticipants had a shared perception that professional knowledge had to be learned in practice. Both M- and L-participants were unhappy with learning in authentic contexts and with self-directed learning; they preferred clear instructions about what to do.

This brings us to answer the third research question about to what extent the qualitative characteristics of the professional knowledge of the students met the requirements for qualification as a new professional BN. According to the European Qualifications Framework (EQF, Europass, n.d.) the new professional BN is competent to independently solve common problems in a creative way and to contribute to the further development of the profession. This requires knowledge as a system of meaning (Wheelahan, 2010). We are inclined to conclude that the intended curriculum based on learning in authentic contexts and self-directed learning did not bring all students up to 
Table 5 Overview of influences of curriculum characteristics on learning professional knowledge as experienced by participants.

\begin{tabular}{|c|c|c|c|c|}
\hline \multirow[b]{2}{*}{$\begin{array}{l}\text { Participant's level } \\
\text { of appraisal of } \\
\text { professional } \\
\text { knowledge }\end{array}$} & \multicolumn{2}{|c|}{$\begin{array}{l}\text { Influence of authentic } \\
\text { contexts as experienced } \\
\text { by participants }\end{array}$} & \multicolumn{2}{|c|}{$\begin{array}{l}\text { Influence of self-directed } \\
\text { learning as experienced } \\
\text { by participants }\end{array}$} \\
\hline & $\begin{array}{l}\text { Knowledge as } \\
\text { instrumental }\end{array}$ & $\begin{array}{l}\text { Knowledge } \\
\text { as a system- } \\
\text { of-meaning }\end{array}$ & $\begin{array}{l}\text { Knowledge as } \\
\text { instrumental }\end{array}$ & $\begin{array}{l}\text { Knowledge } \\
\text { as a system- } \\
\text { of-meaning }\end{array}$ \\
\hline High $(n=3)$ & + & + & + & + \\
\hline High/Medium $(n=3)$ & + & + & + & + \\
\hline Medium (n=8) & + & - & $+/-$ & - \\
\hline Low $(n=2)$ & $+/-$ & - & - & - \\
\hline
\end{tabular}

\begin{tabular}{ll}
\hline+ & $=$ positive influence experienced \\
- & $=$ negative influence experienced \\
$+/-$ & $=$ positive and negative influence experienced
\end{tabular}

that level, see Table 5. However, the EQF does not provide the hard criteria for the presented task that would allow a more precise conclusion.

The experiences in learning reported by the participants offered clues about three factors of interest: intrinsic motivation for learning in higher vocational education, perceptions of learning professional knowledge and the degree or nature of guidance expected from the teacher. These factors seem to affect all four components of Tynjälä's IP-model (Tynjälä, 2008) resulting in vicious or virtuous circles of learning. We compare these three factors per appraisal level in this discussion.

Firstly, motivation for learning seemed to vary across the participants and was related to the knowledge outcome. H-participants' intrinsic motivation was reflected in their enthusiasm to find out own ways of building up and extending their knowledge for their future profession as expected in a constructivist competence-based curriculum. Learning in authentic contexts and self-directed learning as part of the instructional design was supportive to them. HM-participants were also very motivated to learn, but were sometimes disappointed by the lack of support to organise their study activities. H- and HM- participants showed that they developed clinical reasoning skills, one of the most important skills in professional practice in nursing and based on a sturdy knowledge base (Benner et al., 2010; Lambregts et al., 2016). They built up their knowledge as a system of meaning in itself, which enabled them to appropriately select knowledge from their repertoire (Eraut, 1994, 2012; Wheehalan 2010). M-participants appeared intrinsically motivated to learn theoretical knowledge, but learned primarily for good test results. Their instrumental conception of professional knowledge did not enable critical examination of practice. Integration with forms of professional knowledge, like what to do in special circumstances, was missing (Tynjälä et al., 2014). Low scoring M- and the L-participants were motivated to learn knowledge for the tests, but seemed to rely on learning strategies that were superficial and were not conducive to 
the consolidation of what had been learned (Craik, 2002). Consequently, these students built a conceptual theoretical knowledge base too fragile to use for conceptualising practical experiential knowledge, or to build their clinical reasoning skills on.

Secondly, perceptions of learning professional knowledge showed some remarkable variations. In line with the principles underlying the curriculum, H- and HMparticipants shared the perception of responsibility for their own learning. These participants built up their professional knowledge network supported by the study program and were convinced to expand it themselves. Some M-participants had the view that they only had to learn what they immediately would need in practice and were disappointed about the large amount of knowledge they had to learn for the tests; some M- and the L-participants thought that professional knowledge could not be learned "at school", but only in professional practice. Sometimes the latter idea is expressed in practice as well (Bendall, 1976; Kramer, 1974). Kurunsaari et al. (2016) confirmed that students have different views on professional knowledge and that it influences knowledge acquisition. Further, learning in authentic contexts based on written cases disturbed rather than helped the M- and L-participants to build a stable nursing knowledge network.

Lastly, expectations about the role of the teacher differed between the participants. H-participants appreciated when teachers acted as role figures and presented cases from their own nursing practice. They felt challenged when lessons were given in a dialogical way, arguing why something was right or wrong to do. For some tasks they would have preferred more instruction because the assessment form was insufficient to understand what to do. HM-participants shared this opinion, but put emphasis on offering more structure. M-participants missed structure provided by the teacher; not knowing what was expected turned making assessments into a trial and error exercise. Low scoring M- and L-participants had expected much more guidance from the teachers and were dissatisfied about this part of the study program.

The individual process of learning professional knowledge is influenced by interaction between context factors such as instructional designs, personal factors and one's own knowledge views (Gijbels et al., 2005; Hager \& Hodkinson, 2009). The experienced gap between theory and practice in this study can be attributed to the difference between the intended curriculum and the curriculum achieved (Van Merriënboer \& Kirschner, 2018). Therefore, Kostons et al. (2014) advise variation in instructional designs for acquiring knowledge so that cognitive, metacognitive and motivational/ affective learning strategies can be applied and alternated in acquiring sufficient professional knowledge.

\section{Conclusion}

We conclude that learning in a constructivist competence-based curriculum is not beneficial for all participants in this study to meet the requirements of professional knowledge at the end of their program. A third of the participants showed a convincing level of professional knowledge to enter practice, although all students BN had passed their tests. The level of professional knowledge presented in their cases differed. Three factors were discovered influencing the development of a sufficient level of professional knowledge playing a role of vicious or virtuous cycles of knowledge 
development. These are the degree of intrinsic motivation to learn professional knowledge for future profession, the perception of the amount of professional knowledge needed and where to learn it, and the preferred guidance of a teacher in this program. The studied application of instructional design strategies as authentic learning contexts and self-directed learning were effective for $\mathrm{H}$ - and HM-participants to construct their professional knowledge at the required level. M- and L-participants seemed to lack cognitive and metacognitive learning strategies to meet the required knowledge level; as a result the intended curriculum is not achieved by these participants. The results add to the until now modest amount of previous research on learning professional knowledge in a competence-based curriculum using instructional designs like learning in authentic contexts and self-directed learning. It is recommended to vary with instructional designs to meet different views on learning and to conduct new research how cognitive and metacognitive learning strategies can be deployed by students of a university of applied sciences and will contribute to bridge the theory-practice gap.

\section{Limitations}

Considering the method, this study was conducted to gather empirically substantiated knowledge about the learning experiences and knowledge quality outcomes of final year BN students in a competence-based curriculum. The research sample represented the broad variation in students in the programme. The validity in this research is high due to the triangulation of research methods. Furthermore, application of the analysis instruments was done in close cooperation between the first author and the original designer (Van Bommel et al., 2012a, b). Yet, applying the analytic strategies required more professional as well as coding skills than are usually required. The mediocre interrater agreement could be improved by close cooperation between the two coders focussing on clarification of the disagreements revealing uneasiness of the second coder with the very strict classification rules. As a consequence, continuing double coding was considered not feasible as either coding quality or coder independence would suffer. Instead, we decided to formulate improved coding rules based on their discussions. This high dependence on coder skills is a limitation of the present study and replications in the same or comparable domains should take this potential threat to the validity of the study into consideration already in the early stages of study design and preparation.

Results in qualitative research cannot be generalized, but can provide an indication for the same issues in comparable situations. Validity and reliability of results about internal processes of students' thinking cannot be guaranteed. However, direct access to the students' knowledge-in-action in actual practice is hard to achieve in empirical research because nursing professionals cannot always think-aloud during their work with patients and in hectic situations. Indirect access was obtained through reflectionon-action, which is well known to and often used by these students in their study program. By using an own case to reflect on, we came as near as possible to the current professional knowledge of each student and how they applied that. The qualitative method was time-consuming, but enabled an in-depth exploration of answering the research questions. The number of 16 cases was large enough to provide a good representation of the student population. However, subgroups were small, which 
implies that opinions and experiences of an individual student may have unduly influenced the results in their group due to lack of compensation by other voices.

\section{Practical Implications and Further Research}

Based on the outcomes of the present study we recommend to analyse if a curriculum as experienced by the students is the intended curriculum, and to critically evaluate the choice of instructional designs. Educational designers should be aware especially of the unintended and counterproductive effects on low achieving students. Where possible, variation in methods is recommended, by which the students may benefit from more attention for learning cognitive and metacognitive learning strategies so that all new professionals succeed in applying knowledge in practice. The integrative pedagogy model for educational design by Tynjälä et al. (2014) can provide inspiration for teachers and inspire students to deepen their professional knowledge development. Yet, teachers and educational designers should take the poor reflection skills of at least some of the medium and low achieving students into account in choosing applicable methods. Finally, the data in this research are collected from students of one university of applied sciences. It is recommended to expand the research with more participants and into other study programs of Bachelor Nursing, so that empirical findings can indicate ways to bridge the gap between learned theoretical knowledge and effective application in professional nursing practice.

\section{Appendix 1. Attachment: Protocol semi-structured interview}

Welcome the participant. Explain the procedure calmly and clearly, emphasize again that the participant is free to answer and still has the opportunity to leave the research.

Ask for permission to record the conversation. [Start recording].

Identification number

$\operatorname{Sex} \mathrm{M} / \mathrm{F}$

Age in years

Previous education

Years of work experiences

Grade average in study program

1. Thank you for sending me the case. Please tell me more about this case in detail?

- What was the problem; characteristics of the client, home care or hospitalization?

2. Why did you choose this specific case?

3. What was the professional knowledge you needed about the person, the illness, treatment, prevention, pharmacology? Did you need special knowledge about the context before you could take care of this person? 
- Development, physical, psychosocial, spiritual? Cultural?

- Normal behaviour, environment, handicaps, special needs?

4. Please explain in your words which treatment this patient receives?

- Primary process, medical treatment, nursing care, other disciplines, entire care chain?

- Are there ethical issues you have to deal with? Moral dimension?

5. How do you decide to give a new patient the care needed?

- Which nursing interventions do you think of? How to find standards?

- And nursing methods like clinical reasoning, nursing methodology? Which standards/guidelines in your described case? Communication skills, Team of interdisciplinary collaboration? Costs in healthcare?

6. What do you know about quality control in nursing? Healthcare costs? Laws in healthcare with regard to this case?

- Quality control? Laws, other regulation rules, Inspection of healthcare?

- Prevention oriented working, Self-management of illness?

- What is the connection between quality control and your nursing profession?

7. Concept mapping task: write post-its, stick on the paper, organize and connect where possible.

8. Please, fill in this list Body of Knowledge: which items do you recognize, maybe or not?

9. Are there items you want to add to your description of the case or to your concept map? Why/why not?

10. You are one of the first students in this new developed nursing curriculum. What are your learning experiences in the study program?

- Ways of learning, guidance by the teacher, satisfaction level of knowledge? Satisfied with your intentions to learn? Did you learn enough knowledge? What were your own initiatives?

Briefly summarize the conversation and check understanding.

[Stop recording].

Code Availability not applicable.

Authors' Contributions The first author carried out the research conceptualised, planned and conducted the research and analysed the data; the second author assisted in conceptualising the theoretical scope of the article and supervised the project.Data Availability Data will be kept during 5 years at a dedicated server of the OU. It is available for inspection upon request but not for reanalysis due to applicable privacy regulations and agreement with the OU ethical committee. 


\section{Declarations}

Ethical Approval was obtained from the Research Ethics Committee of the Open University (U20190107HVM).

Conflicts of Interest/Competing Interests The selection of the participants was done in cooperation with the examination office of the student's institute. It was explicitly agreed that the institution would have no access to the data, nor influence on any published text.

Open Access This article is licensed under a Creative Commons Attribution 4.0 International License, which permits use, sharing, adaptation, distribution and reproduction in any medium or format, as long as you give appropriate credit to the original author(s) and the source, provide a link to the Creative Commons licence, and indicate if changes were made. The images or other third party material in this article are included in the article's Creative Commons licence, unless indicated otherwise in a credit line to the material. If material is not included in the article's Creative Commons licence and your intended use is not permitted by statutory regulation or exceeds the permitted use, you will need to obtain permission directly from the copyright holder. To view a copy of this licence, visit http://creativecommons.org/licenses/by/4.0/.

\section{References}

Bendall, E. (1976). Learning for reality. Journal of Advanced Nursing, 1, 3-9

Benner, P. (1984). From novice to expert: Excellence and power in clinical nursing practice. Addison-Wesley Benner, P., Sutphen, M., Leonard, V., \& Day, L. (2010). Educating nurses: A call for radical transformation. The Carnegie Foundation

Bereiter, C., \& Scardamalia, M. (1993). Surpassing ourselves: An inquiry into the nature and implications of expertise. Open Court

Bereiter, C. (2002). Education and mind in the knowledge age. Erlbaum

Boshuizen, H. P. A. (2003). Expertise development: How to bridge the gap between school and work (inaugural address). Retrieved October 15, 2020, from https://www.researchgate.net/publication/ 238609150_Expertise_development_how_to_bridge_the_gap_between_school_and_work

Boshuizen, H. P. A., Lehtinen, E., \& Vosniadou, S. (2020). Conceptual changes for and during working life. International Journal of Educational Research, 104, 101682. https://doi.org/10.1016/j.ijer.2020.101682

Brown, V., \& Clarke, V. (2006). Using thematic analysis in psychology. Qualitative Research in Psychology, 3(2), 77-101. https://doi.org/10.1191/1478088706qp063oa

Chi, M. T. H. (1997). Quantifying qualitative analyses of verbal data: A practical guide. The Journal of the Learning Sciences, 6(3), 271-315

Craik, F. I. M. (2002). Levels of processing: Past, present... and future? Memory, 10(5-6), 305-318. https:// doi.org/10.1080/09658210244000135

Creswell, J. W. (2014). Educational research: Planning, conducting and evaluating quantitative and qualitative research (4th ed.) Pearson

Elvira, Q., Imants, J., Dankbaar, B., \& Segers, M. (2017). Designing education for professional expertise development. Scandinavian Journal of Educational Research, 61(2), 187-204. https://doi.org/10.1080/ 00313831.2015 .1119729

Eraut, M. (1994). Developing professional knowledge and competence. Routledge

Eraut, M. (2004). Informal learning in the workplace. Studies in Continuing Education, 26(2), $247-273$. https://doi.org/10.1080/158037042000225245

Eraut, M. (2012). Developing a broader approach to professional learning. In A. Mc Kee \& M. Eraut (Eds.), Learning trajectories, innovations and identity for professional development (pp. 21-45). Springer

Ericsson, K. A., \& Simon, H. A. (1998). How to study thinking in everyday life: Contrasting think-aloud protocols with descriptions and explanations of thinking. Mind, Culture, and Activity, 5(3), 178-186. https://doi.org/10.1207/s15327884mca0503_3

Europass (n.d.). Description of the eight EQF levels. Europass. Retrieved June 8, 2020, from https://europa.eu/ europass/en/description-eight-eqf-levels

Flick, U. (2004). Triangulation in qualitative research. In U. Flick, E. von Kardorff, \& I. Steinke (Eds.), A companion to qualitative research (pp 178-183) (B. Jenner, trans.). Sage 
Gijbels, D., Van de Watering, G., Dochy, F., \& Van den Bossche, P. (2005). The relationship between students' approaches to learning and learning outcomes. European Journal of Psychology of Education, 20(4), 327-341. https://doi.org/10.1007/BF03173560

Gijselaers, W. H., Arts, J. A., Boshuizen, H. P. A., \& Segers, M. S. R. (2006). A trade-off between formal and dynamic knowledge occurs as graduates enter the workplace. In R. De Filippi \& C. Wankel (Eds.), New visions of graduate management education: Research in management education and development (pp. 65-86). Information Age

Gordon, M. (2004). Nursing diagnosis: Process and application. Elsevier

Griffiths, T., \& Guile, D. (2003). A connective model of learning: The implications for work process knowledge. European Educational Research Journal, 2(1), 56-73. https://doi.org/10.2304/eerj.2003.2.1.10

Hager, P., \& Hodkinson, P. (2009). Moving beyond the metaphor of transfer of learning. British Educational Research Journal, 35(4), 619-638. https://doi.org/10.1080/01411920802642371

Hatlevik, I. K. R. (2012). The theory-practice relationship: Reflective skills and theoretical knowledge as key factors in bridging the gap between theory and practice in initial nursing education. Journal of Advanced Nursing, 68(4), 868-877. https://doi.org/10.1111/j.1365-2648.2011.05789.x

Hickman, L. D., DiGiacomo, M., Phillips, J., Rao, A., Newton, P. J., Jackson, E., \& Ferguson, C. (2018). Improving evidence based practice in postgraduate nursing programs: A systematic review. Bridging the evidence practice gap (BRIDGE project). Nurse Education Today, 63, 69-75. https://doi.org/10.1016/j. nedt.2018.01.015

Jossberger, H., Brand-Gruwel, S., van de Wiel, M. W. J., \& Boshuizen, H. P. A. (2018). Exploring students' self-regulated learning in vocational education and training. Vocations and Learning, 11(2), 179-204. https://doi.org/10.1007/s12186-019-09232-1

Kessels, J. (1999). A relational approach to curriculum design. In J. Van den Akker, R. M. Branch, K. Gustafson, N. Nieveen, \& T. Plomp (Eds.), Design approaches and tools in education and training (pp. 59-70). Springer

Kostons, D., Donker, A. S., \& Opdenakker, M.-C. (2014). Self-directed learning in educational practice: A knowledge base for effective strategy instruction. (Dutch). GION. Retrieved August 20, 2021, from https://www.nro.nl/sites/nro/files/migrate/Opdenakker_Zelfgestuurd-leren-in-de-onderwijspraktijk.pdf

Kramer, M. (1974). Reality shock: Why nurses leave nursing. Mosby

Kurunsaari, M., Tynjälä, P., \& Piirainen, A. (2016). Graduating physiotherapy student's conceptions of their own competence. Vocations and Learning, 11, 1-18. https://doi.org/10.1016/j.physio.2016.10.053

Landis, J. R., \& Koch, G. G. (1977). The measurement of observer agreement for categorical data. Biometrics, 33(1), 159-174

Lambregts, J., Grotendorst, A., \& Van Merwijk, C. (Eds.). (2016). Bachelor of Nursing 2020: A future-proof training profile 4.0. Bohn Stafleu van Loghum.

Lave, J. (2009). The practice of learning. In K. Illeris (Ed.), Contemporary theories of learning (pp. 200-208). Routledge

Leinhardt, G., McCarthy Young, K., \& Merriman, J. (1995). Integrating professional knowledge: The theory of practice and the practice of theory. Learning and Instruction, 5(4), 401-408. https://doi.org/10.1016/ 0959-4752(95)00025-9

Maben, J., Latter, S., \& Macleod Clark, J. (2006). The theory-practice gap: Impact of professional-bureaucratic work conflict on newly-qualified nurses. Journal of Advanced Nursing, 55(4), 465-477. https://doi. org/10.1111/j.1365-2648.2006.03939.x

Miles, M. B., \& Huberman, A. M. (1994). Qualitative data analysis: An expanded sourcebook. Sage

Montecinos, C., Walker, H., Rittershaussen, S., Nuñez, C., Contreras, I., \& Solís, M. C. (2011). Defining content for field-based coursework: Contrasting the perspectives of secondary preservice teachers and their teacher preparation curricula. Teaching and Teacher Education, 27(2), 278-288. https://doi.org/10. 1016/j.tate.2010.09.001

Murray, M., Sundin, D., \& Cope, V. (2018). New graduate registered nurses' knowledge of patient safety and practice: A literature review. Journal of Clinical Nursing, 27, 31-47. https://doi.org/10.1111/jocn.13785

Novak, J. D. (2010). Learning, creating and using knowledge: Concept maps as facilitative tools in schools and corporations ( 2 nd ed.). Routledge

Novak, J. D., \& Cañas, A. J. (2008). The theory underlying concept maps and how to construct and use them. Retrieved May 16, 2020, from https://cmap.ihmc.us/docs/theory-of-concept-maps

Ohlsson, S. (2011). Deep learning: How the mind overrides experience. Cambridge University Press

Riemer, V., \& Schrader, C. (2016). Impacts of behavioral engagement and self-monitoring on the development of mental models through serious games: Inferences from in-game measures. Computers in Human Behavior, 64, 264-273. https://doi.org/10.1016/j.chb.2016.06.057

Simons, P. R. J., Van der Linden, J., \& Duffy, T. (Eds.). (2000). New learning. Kluwer 
Smeby, J.-C., \& Vågan, A. (2008). Recontextualising professional knowledge: Newly qualified nurses and physicians. Journal of Education and Work, 21(2), 159-173. https://doi.org/10.1080/ 13639080802018014

Ten Hoeve, Y., Castelein, S., Jansen, W. S., Jansen, G. J., \& Roodbol, P. F. (2017). Nursing students' changing orientation and attitudes towards nursing during education: A two year longitudinal study. Nurse Education Today, 48, 19-24. https://doi.org/10.1016/j.nedt.2016.09.009

Tynjälä, P., Slotte, V., Nieminen, J., Lonka, K., \& Olkinuora, E. (2006). From university to working life: Graduates' workplace skills in practice. In P. Tynjälä, J. Välimaa, \& G. Boulton-Lewis (Eds.), Higher education and working life: Collaborations, confrontations and challenges, (pp. 73-88). Elsevier

Tynjälä, P. (2008). Perspectives into learning at the workplace. Educational Research Review, 3, $130-154$. https://doi.org/10.1016/j.edurev.2007.12.001

Tynjälä, P., Häkkinen, P., \& Hämäläinen, R. (2014). TEL@work: Toward integration of theory and practice. British Journal of Educational Technology, 45(6), 990-1000. https://doi.org/10.1111/bjet.12164

Valcke, M. (2017). Education as design science: An introduction for instructional developers and future teachers (5th. ed.)(Dutch). Academia.

Van Bommel, M., Boshuizen, H. P. A., \& Kwakman, K. (2012a). Appraising the qualities of social work students' theoretical knowledge: A qualitative exploration. Vocations and Learning, 5(3), 277-295. https://oi.org/10.1007/s12186-012-9078-9

Van Bommel, M., Kwakman, K., \& Boshuizen, H. P. A. (2012b). Experiences of social work students with learning theoretical knowledge in constructivist higher vocational education: A qualitative exploration. Journal of Vocational Education \& Training, 64(4), 529-542. https://doi.org/10.1080/13636820.2012.727857

Van Merriënboer, J. J. G., \& Kirschner, P. A. (2018). Ten steps to complex learning: A systematic approach to four-component instructional design (3rd ed.). Routledge

Van Merriënboer, J. J. G., Van der Klink, M. R., \& Hendriks, M. (2002). Competences: From complications to compromise: About sliders and limiters (Dutch). Retrieved 18 June, 2020, from https://www. onderwijsraad.nl/upload/publicaties/414/documenten/studie competenties.Pdf

Verberk, F., \& Merks, A. (2016). Nursing according to the Neuman systems model: Translation and adaptation for Dutch practice (6th ed.) Koninklijke van Gorcum

Virtanen, A., Tynjälä, P., \& Eteläpelto, A. (2014). Factors promoting vocational students' learning at work: Study on student experiences. Journal of Education and Work, 27(1), 43-70. https://doi.org/10.1080/ 13639080.2012.718748

Wenger, E. (1998). Communities of practice: Learning, meaning and identity. Cambridge University

Wheelahan, L. (2010). Why knowledge matters in curriculum: A social realist argument. Routledge

WHO (2001). International Classification of Functioning, Disability and Health (ICF). Retrieved June 3, 2020, from https://www.who.int/standards/classifications/international-classification-of-functioning-disabilityand-health

Zimmerman, B. J., \& Schunk, D. H. (Eds.). (2011). Handbook of self-regulation of learning and performance. Routledge

Publisher's Note Springer Nature remains neutral with regard to jurisdictional claims in published maps and institutional affiliations.

Ria den Hertog $\mathrm{PhD}$ is a lecturer and researcher at the Christian University of Applied Sciences, Faculty of Healthcare in Ede, the Netherlands. She teaches nursing, nursing ethics, and research methodology and holds a MSc degree in nursing from the University Utrecht and a MSc degree in educational sciences of the Open University of the Netherlands. She earned her $\mathrm{PhD}$ degree from the VU University Amsterdam with a thesis entitled Patient preferences in nursing decision-making. A theory about fine-tuning knowledge in acute care.

Henny P. A. Boshuizen is emeritus professor Educational Sciences of the Open University of the Netherlands. She holds a BSc and MSc degree in psychology from the University of Amsterdam and a PhD from Maastricht University. Her research regards the development of professional expertise in several domains, the associated learning processes and required cognitive changes, and educational strategies to support learners on their way to expertise. 